\title{
Remaking Practices in the Redesign of a Primary Healthcare Program
}

\author{
J Rule, R Dunston and N Solomon
}

\author{
Abstract \\ Objective: To develop a detailed account of \\ changed practices in everyday work in the redesign \\ of a primary healthcare program.
}

Design: The research aimed to produce layered and rich descriptions of the complex and multidimensional remaking of health practices. Empirical data was gathered through ethnographic methods including; interviewing, self-reporting, observation and shadowing. The subjects of the research were involved as active participants in the research design, data gathering and analysis.

Setting: HealthOne was a New South Wales government attempt to provide a local and responsive model to improve chronic disease management in primary and community healthcare settings. We report specifically on the HealthOne program implemented in a suburb of Western Sydney.

Main outcome measures: The research did not aim to evaluate the program but to uncover instances of professional learning though identifying changes in professional practice. These were noted and observed by the researchers and research participants or through reflexive conversations with the program planners, healthcare workers and the research team.

Results: Drawing on the work of a number of learning and practice-based theory writers, particularly those using a socio-material approach, we describe how practice change has occurred and how work practices have been remade at this site - especially in the role of the General Practice Liaison Nurse (GPLN).

Conclusions: The research demonstrated the potential for new categories and practices of health work to emerge; this was especially seen in the work of the GPLN but also extended to new ways of working through General Practitioners and community health networks.

Abbreviations: GP - General Practitioner;

GPLN - General Practice Liaison Nurse.

Key words: primary healthcare; service redesign; qualitative research; practice change.

\section{John Rule}

University of Technology

Sydney, New South Wales, Australia.

\section{Roger Dunston}

University of Technology

Sydney, New South Wales, Australia.

\section{Nicky Solomon}

University of Technology

Sydney, New South Wales, Australia.

Correspondence:

John.Rule-1@uts.edu.au

\section{Introduction}

In this paper we explore the complex and multi-dimensional remaking of primary healthcare practices. The specific setting for the research was a suburb in Western Sydney where a new program was to be implemented. Rapid change in community and primary healthcare funding and policy approaches at all levels of government was evident at the time the program was implemented. The research is reported from a study conducted by a multi-disciplinary team from the University of Technology Sydney (UTS) supported by an Australian Research Council Linkage grant (LP 100200435) with the industry partner organisation being the New South Wales Department of Health. This paper reports on one site in Western Sydney; the specific site is not named in this paper. 
Fieldwork was conducted in 2011 and 2012 and the site was one of the first places in which the state-wide New South Wales HealthOne program was implemented. Since that time 25 operational HealthOne service sites have been developed throughout New South Wales. The research reported here should be of interest therefore to academics as well as health managers, field staff and other health professionals interested in primary and community healthcare.

The research did not aim to assess professional competence, leadership or management styles. Rather, the research approach was one that tried to stay alert to emergent and new practices that might be observed in a primary healthcare setting as program redesign was occurring.

\section{Background}

Coordination and integration of care arrangements within community settings have been an area of policy focus by many levels of government and team-based models of primary care and have been receiving particular attention since 2000. [1,2,3,4] The development of successful integrated primary and community healthcare programs is of significant national and international policy interest and it has been argued that primary healthcare still has the potential to be responsive - through partnership approaches, through the development of new practice models and through innovative care coordination in GP and community health settings. [5]

The complexities of health practice change as framed by the policy expectations above cannot be underestimated. The research on HealthOne provides an opportunity to fill in some details of a noted gap in empirical research - on how change can be designed and implemented in primary healthcare settings. This paper provides some details of how practice change can be understood as an accomplishment of change in everyday situated action.

A concurrent study in another Western Sydney suburb provided evidence of the important role of the General Practice Liaison Nurse (GPLN) in improving coordination and integration of care for patients. [6] The findings were consistent with other studies that have investigated the value of nurse-led, non-General Practitioner (GP) staff involvement and team based approaches to the management of chronic illness. $[7,8,9]$ These studies have noted that more nurseled collaborative models to meet the needs of patients in general practice contexts have been called for but some real barriers have been identified. One barrier is that not everyone shares the same assumptions about potential success of team-based patient management and another noted that changes at a practice level did not necessarily mean changes in quality of care would be experienced at a patient level. Changed practices take time to implement and observe - our research and this paper contributes to an emerging knowledge base of attempts at implementing change and integrating services in local primary and community healthcare settings.

\section{Method}

This paper draws on data gathered using ethnographic methods including: interviewing; self-reporting; observation and shadowing. These were supported by participatory research methods, such as workshops, focus groups and participant selection of relevant data, as well as digital, written and document recording of practice events. Every attempt was made through this approach to understand the world as others see it, experience it and act in it. These methods were an attempt by the research team to 'get close to daily practice.' $[10,11]$

Human research ethics approval was obtained from the UTS and relevant NSW Local Health District authorities. Senior NSW Department of Health planners provided research data through interviews and facilitated meetings and negotiations on the conduct of the research between the research team and those working at this specific HealthOne site. There were more than fifteen site visits, several onsite team meetings with researchers and HealthOne staff; fifty interviews were conducted and over twenty researcher activities such as shadowing were recorded. Policy, organisational and clinical practice documents were also reviewed. Most data was gathered in 2011 and 2012, review of the research data by the research team, industry partners and the research participants continued during 2013 through to 2015.

In this paper we have used analytical and conceptual tools available from disciplinary areas studying inter-professional, organisational and workplace learning that describe practices as something that is possible to identify and analyse - practices may be emergent, complex and dynamic. [12,13] A socio-material approach to practice and research does not prescribe a clear cut procedure for analysing and presenting evidence [14] With that in mind the selection of quotes and data provided below from the research participants does not attempt to provide a representative account of what was said by all participants. Rather, as presented below the data identifies the traces of change that have been observed or noted by the research participants themselves. 
Much of what constitutes 'practice', in the sense we are using the word, is tacit or unconscious. Although new practices are sometimes displayed consciously they can best be understood retrospectively, and, emerging practices always remains contingent and subject to change at any time. $[15,16]$ This supports the understanding that practices emerge as a result of contextual socio-material conditions in which actions are taking place: contrasting with conventional approaches that place the development of guidelines, written policies and standard operating procedures at the centre of trying to bring about changes in practice. [17]

\section{Findings}

A point of view expressed by many working at the site was that GP services and community health services were under-resourced and under siege because of changing policy directions and that change for the better, or finding new ways of working was not possible in the current environment. Other research participants suggested that incremental change was still possible, providing the various players were prepared to act as joint partners in this change process. Some who were engaged in the development of the program - including the program planners and those working at the research site - used the imagery of a change journey to describe what was happening as HealthOne was implemented and indicated their willingness to engage in the journey of change.

In the following sections we describe the changed role of the GPLNs and identify that the program planners had to adopt a specific leadership style to implement the program. References are made to Table 1, containing selected extracts from interviews to support these findings.

The GPLN role was not entirely new - the role had existed as part of the concept of care navigation and continuing-care nurse consultants operating from hospital services and in some of the Local Area Health Services in Western Sydney area.

However the consolidation of the GPLN nurse in a clinical setting was new, and was a practice that we can describe as being 'remade' and consolidated at the research site. Some of the program planners noted that the process of developing HealthOne needed to be organic and come from people who were working at local sites. However this came up against a stark reality at the service delivery level that there was a high turnover of staff in the initial two years of the project and there was confusion over the grading of the GPLN positions.
Both of these practical impediments of staffing changes and uncertainty in grading of related positions undermined the team building processes that were to be central to the program. Additionally resources were not always available to advertise the potential activities of HealthOne or the GPLN role, so that the capacity within the community health sector to interact with the new service model or for outreach from the site was at times restricted by funding constraints.

As an addition to the coordination of care management for complex health issues the GPLNs in interviews and meetings used a particular type of language - replete with notions of extending, sharing, collaborating and 'being a conduit' - to describe their work within the program. They described their work with patients and clients but also clearly described the impact that they intended to have on the ways that GPs would function - by seeking to assist GPs in particular referral pathways and through better coordination and more efficient patient management. Clearly, in this way the GPLNs were intending to be recognised as part of a team for management of patients and clients with chronic illness and conditions. (See Table $1-a, b, c$ and d.)

Meeting with GPs working in the community and trying to formalise that relationship and pathways with HealthOne was a major challenge. Another barrier, for engagement of GPs included the potential that HealthOne was seen as a 'competitor' in the service landscape. (See Table 1 below - $d$, e and f.) In effect HealthOne was a program that not only had to engage clients but had to engage other operators in the local health system through communication, collaboration and cooperation to ensure that goals were achieved. (See Table $1-\mathrm{a}, \mathrm{f}$ and $\mathrm{g}$.)

To bring about the required changes in the program we observed that the planners of HealthOne were also drawing upon ideas of collective and relational leadership. [18,19] The planners did this by encouraging a culture of shared responsibility for the program; not only amongst those employed directly by HealthOne such as the GPLNs but through encouraging dialogue and discussion across other program areas into community health and with GPs working as private providers. Often the program planners were involved in advocating for the use of the service through Local Health Districts and through formalised GP networks. Good communication, extensive interaction and trying 'open up thinking' were the styles most valued and enacted by the program planners. (See Table $1-d$, e and $f$ ) 
Table 1: Selected extracts from interviews with program planners and the GPLNs

\begin{tabular}{|l|l|l|}
\hline $\begin{array}{l}\text { IN TEXT } \\
\text { IDENTIFIER }\end{array}$ & SPEAKER & EXTRACT FROM INTERVIEW \\
\hline a. & Program planner & $\begin{array}{l}\text { The critical positions that make HealthOne work are the GP liaison. They're the entry } \\
\text { point, they're the cross-over, and that's been a really important initiative. }\end{array}$ \\
\hline b. & GPLN & $\begin{array}{l}\text { My main role is to offer support to the GPs in managing their clients with existing } \\
\text { chronic disease...to capture the clients of GPs that present more than three times } \\
\text { in twelve months to hospital and to orient them [GPs] to services in the community, } \\
\text { such as the services we offer for diabetes, continence clinic....resources for mental } \\
\text { health... }\end{array}$ \\
\hline c. & GPLN & $\begin{array}{l}\text { We're meant to be looking at prevention, education, all of those factors that come } \\
\text { under the management of chronic disease. }\end{array}$ \\
\hline d. & Program planner & $\begin{array}{l}\text { As part of the HealthOne model, we [in community health] are expecting the myriad } \\
\text { of GPs that are out there in GP land to communicate, interact and work with us as a } \\
\text { service provider. So this is a new type of service. }\end{array}$ \\
\hline e. & $\begin{array}{l}\text { We've had to recognise that GPs are a business and we probably have to put ourselves } \\
\text { out a bit to support them in their business, in order to open up their thinking a bit... } \\
\text { to be doing things differently. }\end{array}$ \\
\hline f. & Program planner & $\begin{array}{l}\text { We're going to be connecting them up differently and we're going to start with our } \\
\text { Community Health Leaders and our GP leaders working together to really identify } \\
\text { what are the things that they both really care about. }\end{array}$ \\
\hline
\end{tabular}

HealthOne was an attempt to develop a new practice model and engage GPs in coordinating with community health services in new and specific ways. Through the research it was possible to identify a re-making of the partnership and professional roles of the GPLNs and GPs in primary health services. Figure One demonstrates the range of partners and stakeholders that were meant to be engaged in HealthOne activities and this includes, amongst others; NonGovernment Organisations, the Local Health Districts, the
Divisions of General Practice, Aboriginal Medical Services as well as GPs working in the private sector. [20]

The aim of HealthOne was to build connections between different parts of the health system and enhance the provision of primary community healthcare across populations. The governance and accountability systems outlined in the HealthOne guideline documents were perhaps more aspirational rather than evidenced in

Figure 1: HealthOne NSW governance: range of stakeholders

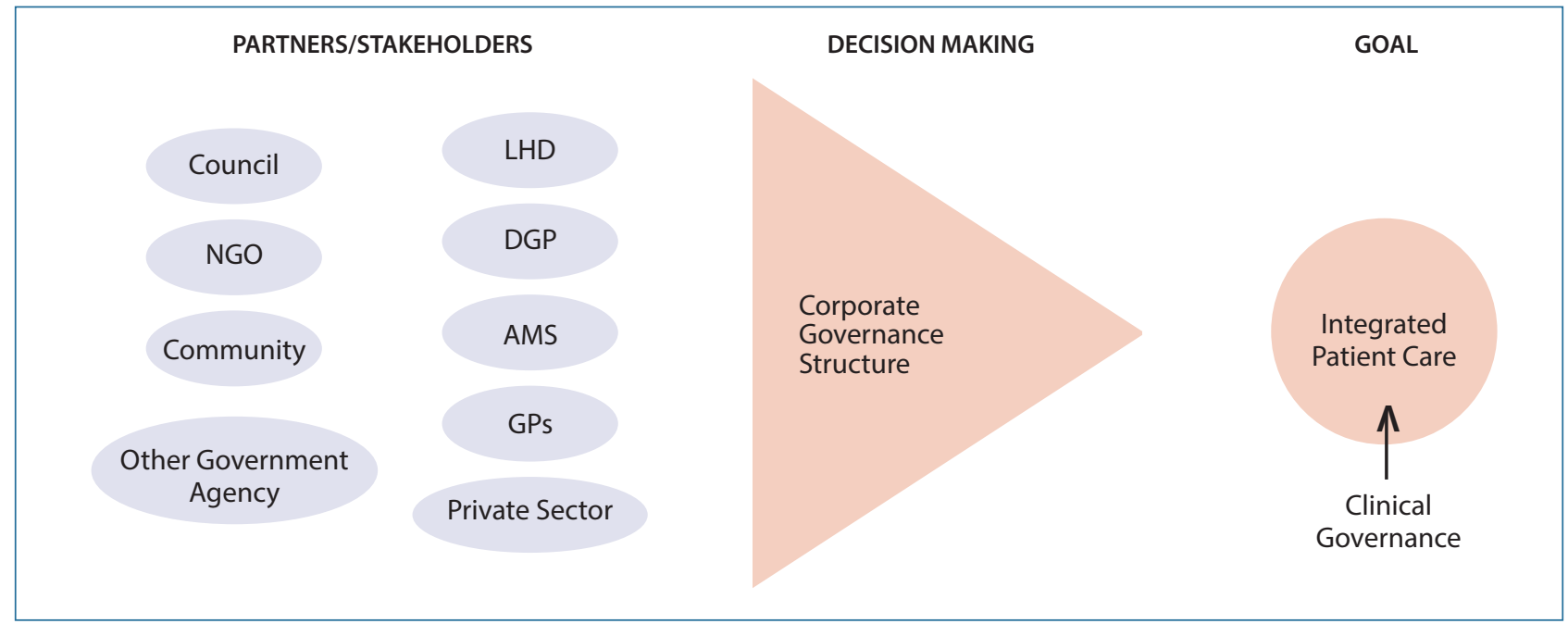


practice. One of the regular comments from those who were operating within the site was a perceived sense of distance from the centre of the change process. High staff turnover and the complications over grading of the new positions could provide some explanation for this. Another reason why accountability mechanisms were never completely transparent for those at the site, was the generalised sense that community health services were 'under siege', with expectations of further funding reductions.

\section{Discussion}

Given the context of continual change in which HealthOne was being placed, it is clear that we were investigating a situation where, as argued by some practice-based theorists changing practices are neither discrete nor stable. [14,17] Innovative practice is a continuous process, one that stops and starts and has many twists according to the situation in which it is occurring - this is a very different view to traditional formal planning processes or logic framework approaches and has significant implications for health service delivery redesign. Redesigning change in this particular setting was far more complicated than a 'Plan, Do, Study, Act' action learning and research model - which it has been argued is, anyway, rarely ever rigorously applied in healthcare settings. [21]

A significant observation by the academic research team members was that their initial assumption that a 'space for learning' would be available within the service redesign process was mistaken. There remained a persistent gap at the research site for time to 'step out' of the process of being engaged in the rapidly changing service activities and reflect on the learning that was taking place. In this sense one of the aims of the research - that of identifying what supports professional learning as change is taking place was never completely realised. The process of rapid change at the research site, without time set aside for those involved to reflect on the process of change was a program limitation and consequently appears as a limitation in what the research was able to achieve.

The conditions which impacted on practices emerging included: stability; local condition responses and changes; there were times of instability and disturbances; and at various stages where there are attempts to codify emergent practices. Lengthy written documents were developed to respond to the many contingencies that the HealthOne initiatives faced and were instrumental in trying to guide field workers; but their effectiveness appeared limited and are best understood as one of a number of factors that impacted on service redesign.
Much of the language in the guiding documents for HealthOne talked of the importance of teamwork through the collaboration, coordination and cooperation of healthcare workers. [22] Team-based approaches in primary healthcare settings for the management of specific chronic diseases have already been attempted and evaluated, for example the area of diabetes and cardiovascular diseases. [23] There are calls for studies of longer duration than the one we have undertaken and that more systematic evaluation methodologies on the impact of primary healthcare teams have been called for. [24,25]

A limitation of this study is that it followed the changes and development of HealthOne only in the formative stages of the program. Obvious concerns that emerged within the program; such as, staff turnover and, for example, sustainability of the GPLN positions were unable to be conclusively addressed within the remit of the study design. It is worth noting that the GPLN positions have been maintained since the research commenced, but due to further reform are nested within a new program description. A major recommendation arising from this study would be for further, longitudinal studies at specific sites which could focus on the how to maintain innovative work practices as pathways are being disrupted and then re-formed.

\section{Conclusion}

HealthOne was in part a response to the regular calls for coordination, integration and team-based approaches to be a feature of the delivery of primary and community healthcare. As a program intervention HealthOne could be described as an attempt to remake or change accepted or standard practices in community and primary healthcare - an attempt to remake practices in an integrated and coordinated manner - the remaking and consolidation of the practices of the GPLN and the different ways that GPs were involved were central to that. New ways of working and different approaches between professional groupings were attempted.

Managing program redesign and change in such a complicated and dynamic environment as primary and community healthcare is challenging. Contextual factors have to be taken into account; the changing policy environment, changing populations, and changing funding structures. We argue though, that practices were remade in the HealthOne program as new healthcare worker roles and relationships were performed at this particular site. This research, even though it occurred in a context of rapid change and 'reform exhaustion' in the health sector, provides evidence of the potential for new and locally responsive 
programs to continue to be developed in primary and community healthcare.

\section{Competing interests}

The authors declare that they have no competing interests.

\section{References}

1. World Health Organisation. Innovative Care for Chronic Conditions: Building Blocks for Action, Global Report 2002 [accessed April 1, 2016]. Geneva: World Health Organisation; 2001. Available from: $<$ http://www.improvingchroniccare.org/downloads/ who_innovative_care_for_chronic_conditions.pdf>

2. World Health Organisation. The World Health Report 2008: Primary Healthcare (now more than ever) [accessed April 1, 2016]. Geneva: World Health Organisation; 2008. Available from: <http://www. who.int/whr/2008/en/>

3. Kalucy L. Editorial: four planning challenges from diverse research studies. Aust J Prim Health. 2011;17(3):209.

4. Harris M, Kidd M, Snowdon T. New models of primary and community care to meet the challenges of chronic disease prevention and management: a discussion paper for NHHRC [accessed April 1, 2016]. University of New South Wales: Sydney, NSW. 2008 Jul. Available from: <http://www.health.gov.au/ internet/nhhrc/publishing.nsf/content/.pdf >

5. Jackson C. Our first National Primary Healthcare Strategy: 3 years on, what change for general practice? Med J Aust; 2013;198(11): 581-582.

6. McNab J, Paterson J, Fernyhough J, Hughes R. The Role of the General Practitioner Liaison Nurse in a Community Health Program to improve integration and coordination of services for the chronically ill [accessed April 1, 2016]. Aust J Prim Health. 2014. Available from: <http://dx.doi.org/10.1071/PY14089>

7. Harris MF, Jayasinghe UW, Taggart JR, Christl B, Proudfoot JG, Crookes PA, Beilby JJ, Davies GP. Multidisciplinary team care arrangements in the management of patients with chronic disease in Australian general practice. Med J Aust. 2011;194(5):236-9.

8. Black DA, Taggart J, Jayasinghe UW, Proudfoot J, Crookes $P_{t}$ Beilby J, Powell-Davis G, Wilson LA, Harris MF. Teamwork Research Team. The Teamwork Study: enhancing the role of non-GP staff in chronic disease management in general practice. Aust J Prim Health. 2013;19(3): 184-9.

9. Hegney DG, Patterson E, Eley DS, Mahomed R, Young J. The feasibility, acceptability and sustainability of nurse-led chronic disease management in Australian general practice: the perspectives of key stakeholders. Int J Nurs Pract. 2013;19(1):54-9.

10. McIntyre A. Participatory action research. Los Angeles: Sage Publications; 2008

11. Israel BA, Schulz AJ, Parker EA, Becker AB. Community-based participatory research: policy recommendations for promoting a partnership approach in health research. Educ for Health (Abington). 2001;14(2):182-97.

12. Brown JS, Duguid P. Organizational learning and communities of practice: toward a unified view of working, learning, and innovation. Organization science. 1991;2(1):40-57.

13. Schatzki TR. On organizations as they happen. Organization Studies. 2006;27(12):1863-73.

14. Fenwick T. Workplace learning: emerging trends and new perspectives. New Directions for Adult and Continuing Education. 2008;(119):17-26.

15. Feldman MS, Orlikowski WJ. Theorizing practice and practicing theory. Organization Science. 2011;22(5):1240-53.
16. Price OM, Johnsson MC, Scheeres H, Boud D, Solomon N. Learning organizational practices that persist, perpetuate and change: a Schatzkian view. In Practice, Learning and Change. Netherlands: Springer; 2012. pp. 233-247.

17. Gherardi S. Knowing and learning in practice-based studies: an introduction. The Learning Organization. 2009;16(5):352-9.

18. West M, Eckert R, Steward K, Pasmore B. Developing collective leadership for healthcare [accessed April 1, 2016] . London: The King's Fund; 2014. Available from: <http://www.kingsfund.org.uk/ sites/files/kf/field/field_publication_file/developing-collectiveleadership-kingsfundmay 14 . pdf>

19. Harden H, Fulop L. The challenges of a relational leadership and the implications for efficacious decision-making in healthcare. Aust Pac J Health Manag. 2015;10(3):SI51.

20. NSW Department of Health. Guidelines for Developing HealthOne NSW Services Version 1.1 [accessed April 1, 2016]. Sydney: NSW Department of Health; 2012. Available from: <http://www.health. nsw.gov.au/healthone/Documents/honswguidedevelop_11.pdf>

21. Taylor MJ, McNicholas C, Nicolay C, Darzi A, Bell D, Reed JE. Systematic review of the application of the plan-do-study-act method to improve quality in healthcare. BMJ Qual Saf. 2014; 23(4):290-8.

22. NSW Department of Health. Guidelines for Developing Governance Arrangements for HealthOne NSW Services [accessed April 1, 2016]. Sydney: NSW Department of Health; 2011. Available from: <http://www.health.nsw.gov.au/healthone/Publications/ healthone-governanceguidelines.pdf>

23. Eley DS, Patterson E, Young J, Fahey PP, Del Mar CB, Hegney DG, et al. Outcomes and opportunities: a nurse-led model of chronic disease management in Australian general practice. Aust J Prim Health. 2013;19(2):150-8.

24. Black DA, Taggart J, Jayasinghe UW, Proudfoot J, Crookes P, Beilby J, et al. The Teamwork Study: enhancing the role of non-GP staff in chronic disease management in general practice. Aust J Prim Health. 2013;19(3):184-9.

25. Naccarella L, Greenstock LN, Brooks PM. A framework to support team-based models of primary care within the Australian healthcare system. Med J Aust. 2013;199(5 Suppl):S22-5. 